\title{
Bench-to-beside review: Acute-on-chronic liver failure - linking the gut, liver and systemic circulation
}

\author{
Len Verbeke*, Frederik Nevens and Wim Laleman
}

\begin{abstract}
The concept of acute-on-chronic liver failure (ACLF) was introduced recently to describe a subset of patients with chronic liver disease presenting with profound deterioration of liver function and rapidly evolving multi-organ failure. ACLF is frequently accompanied by the development of severe inflammatory response syndrome and has a high mortality. To date, treatment options are limited and exclusively supportive. Over the last few years, some insights have been generated in the pathophysiology of ACLF. A key role for the interaction of innate immune dysfunction, enhanced bacterial translocation from the gut, and circulatory dysfunction has been proposed. In this respect, therapeutic strategies have been examined, with variable success, in experimental studies in animals and humans. This review focuses on potentially relevant pathophysiological elements in the development of ACLF and points out promising treatment modalities in ACLF.
\end{abstract}

\section{Introduction and clinical background}

The concept of acute-on-chronic liver failure (ACLF) was introduced in 1995 and gradually has received more attention since the introduction of albumin dialysis [1]. In its early definition, it was described as a rapid deterioration of liver function in a patient with previously well-compensated liver disease, usually provoked by an acute insult. This insult could be either primarily hepatotoxic or indirect due to variceal bleeding or infection [2]. The primary hepatotoxic causes of ACLF differ among different geographical areas. In Western countries, acute alcoholic liver disease is common, and reported

*Correspondence: len.verbeke@med.kuleuven.be

Department of Liver and Biliopancreatic Disorders, University Hospital Gasthuisberg, K.U. Leuven, Herestraat 49, B-3000 Leuven, Belgium prevalence varies between $39 \%$ and $92 \%$ [3,4]. In Asia, mostly hepatitis $B$ reactivation or the intake of hepatotoxic drugs is reported in the literature [5,6]. On the Indian subcontinent, a high incidence of hepatitis $\mathrm{E}$ superinfection was proposed in the etiology of ACLF [7].

The definition of ACLF is a matter of ongoing debate. In 2008, the Asian Pacific Association for the Study of the Liver proposed a consensus guideline defining the concept of ACLF [8]. In that paper, liver failure was defined as the development of jaundice and coagulopathy, complicated by ascites or encephalopathy or both within a time frame of 4 weeks. Remarkably, in this expert consensus definition, the precipitating event leading to ACLF was obligatory hepatic in origin. Thus, this definition excluded liver failure elicited by infection or gastrointestinal bleeding. Alternatively, in the recent literature in the West, ACLF is regarded more as a systemic complication of chronic liver disease since its clinical presentation is almost invariably accompanied by hemodynamic alterations, kidney failure, multi-organ failure, and inflammatory changes mimicking severe inflammatory response syndrome (SIRS) $[2,3]$.

ACLF differs from chronic hepatic decompensation (CHD) in two key elements. First, the development of liver failure and end-organ dysfunction in ACLF is much faster than in CHD. In the literature, this period ranges from 2 to 12 weeks $[2,3,8,9]$. Second (and maybe of more importance), in ACLF, there is still a chance of recovery of liver function. This is illustrated by clinical data in our prospective clinical cohort study, in which $54 \%$ of patients with ACLF survived hospitalization, and transplant-free survival rates in time matched those of comparable patients with CHD [3].

The high prevalence and mortality rates associated with ACLF make it an important health-care issue and, owing to the use of the MELD (Model for End-Stage Liver Disease) scoring system, renew interest in liver transplantation. In reported literature, short-term mortality rates vary from $46 \%$ to $89 \%$ [10]. Mortality in ACLF is closely related to the development of SIRS in patients, irrespective of the severity of liver disease [3,11]. 


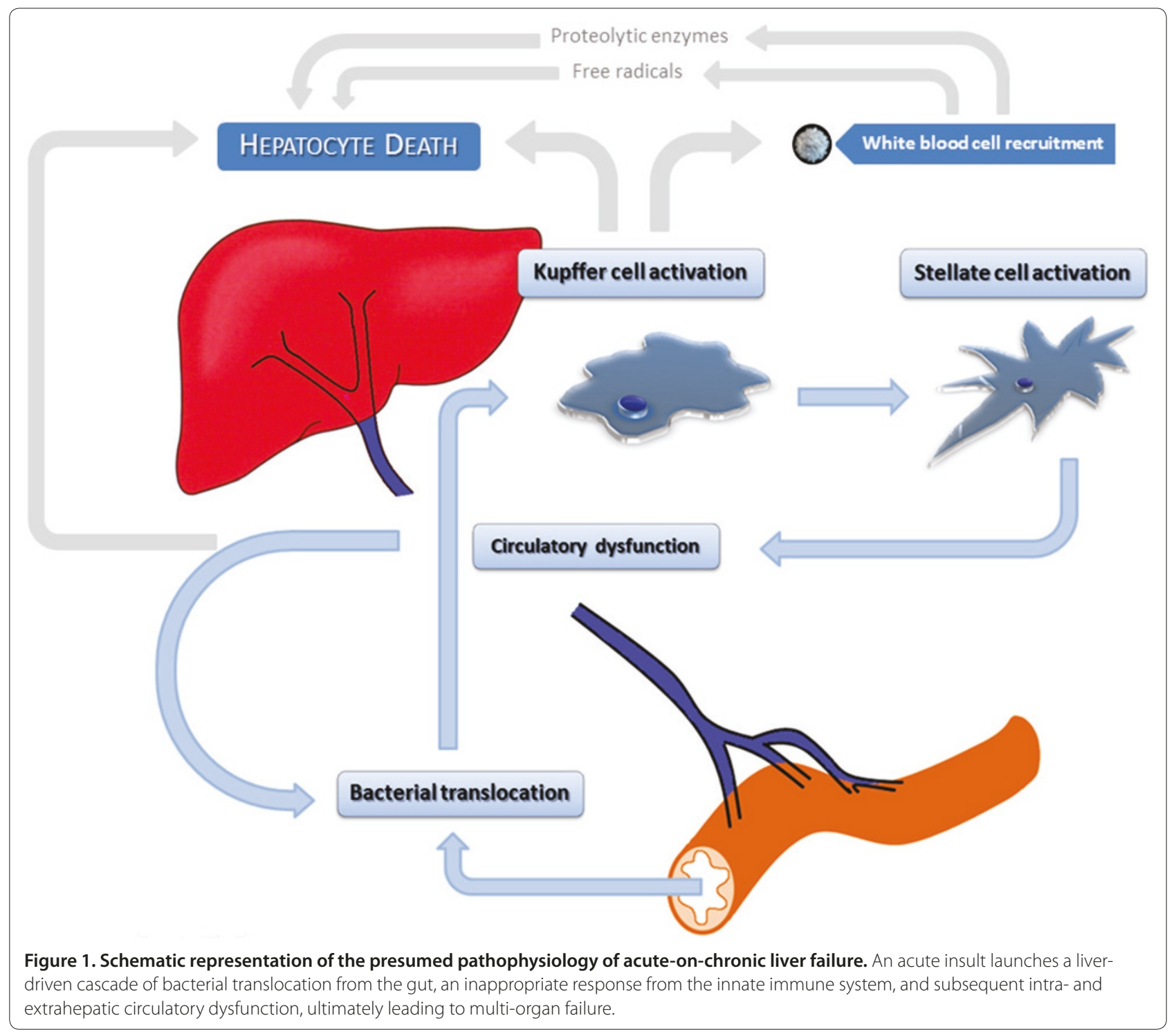

Pathophysiology of acute-on-chronic liver failure Three main mechanisms are currently proposed as key elements in the development of ACLF: immune dysfunction, intestinal bacterial translocation, and circulatory dysfunction (Figure 1). We will discuss each of these elements separately and point out important interactions in the context of ACLF.

\section{Innate immune dysfunction}

\section{The innate immune system and Kupffer cells}

The innate immune system serves as a first-line defense mechanism against bacteria and toxins. It generates a non-pathogen-specific inflammatory response after stimulation with highly conserved antigens, such as lipopolysaccharides (LPSs). The main effector cells of the innate immune system are phagocytic cells, such as macrophages, neutrophils, and monocytes. The main cellular components of the innate immune system within the liver are the Kupffer cells. The liver is extremely important in innate immunity since Kupffer cells represent $80 \%$ to $90 \%$ of the tissue macrophages in the human body [12]. The strategic location of Kupffer cells within the lumen of the liver sinusoids and the anatomical location of the liver as a first-line station for bacteria and toxins derived from the gut further stress the importance of the liver as a strategic immunological organ.

\section{Classic mechanism of Kupffer cell activation}

Several basic scientific data support the concept of innate immune dysfunction on the cellular and molecular level in ACLF. The main orchestrator of immune dysfunction in liver disease has proven to be the Kupffer cell 


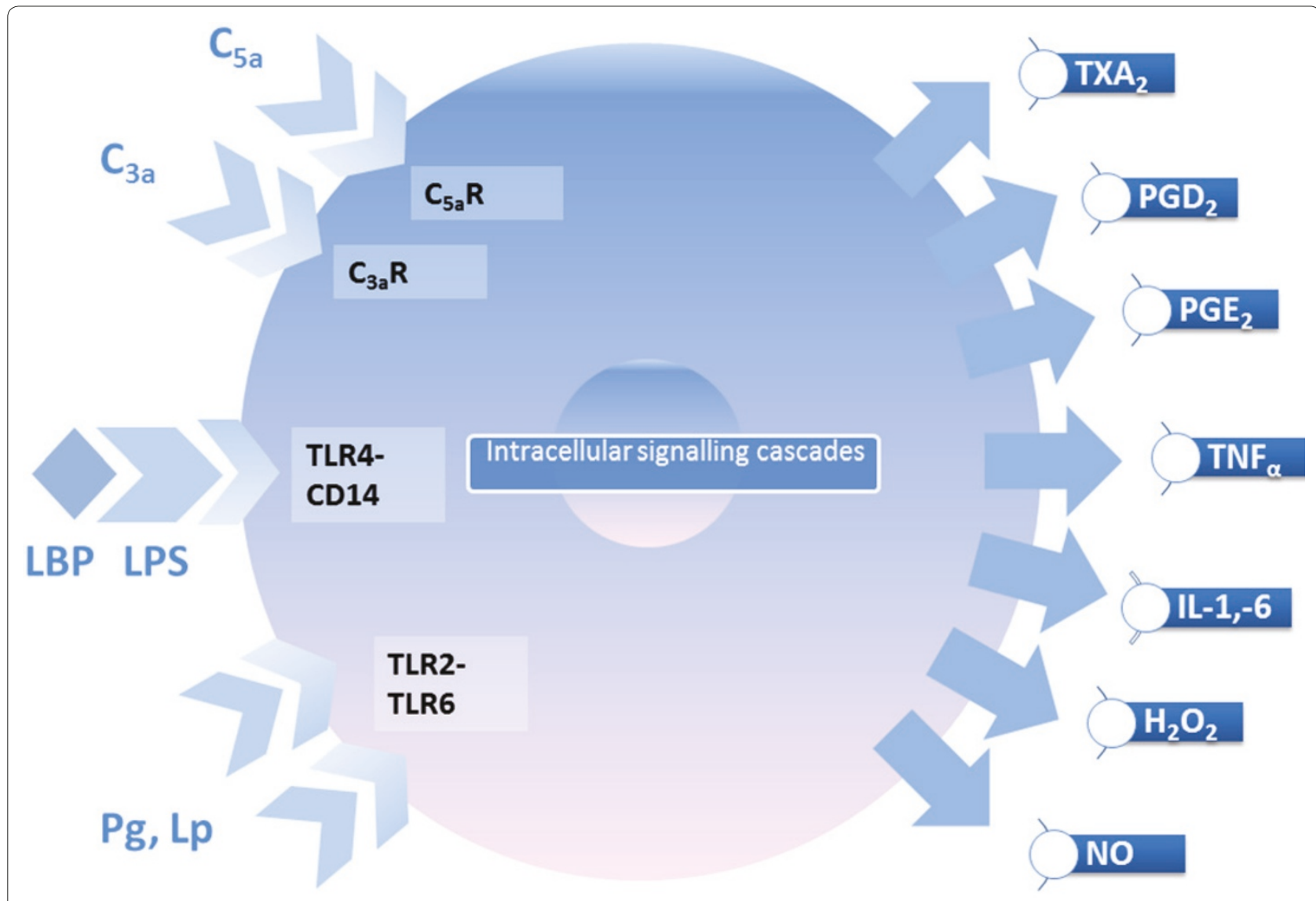

Figure 2. Mechanisms of Kupffer cell activation. IL, interleukin; LBP, lipopolysaccharide-binding protein; Lp, lipoproteins; NO, nitric oxide; Pg, peptidoglycans; $\mathrm{PGD}_{2^{\prime}}$, prostaglandin $\mathrm{D}_{2^{\prime}} ; \mathrm{PGE}_{2^{\prime}}$ prostaglandin $\mathrm{E}_{2^{\prime}}$ TLR, Toll-like receptor; $T N F a$, tumor necrosis factor-alpha; $T X \mathrm{~A}_{2^{\prime}}$, thromboxane $\mathrm{A}_{2}$.

(Figure 2). Kupffer cells in healthy liver exert many roles: they intervene in hemoglobin degradation, phagocytize bacteria and damaged cells, serve as antigen-presenting cells, and eliminate toxins such as ethanol [12,13]. Importantly, they interact intensively with other cells such as immune cells, sinusoidal endothelial cells, hepatocytes, and stellate cells, especially once they are activated. Kupffer cells are activated by many different stimuli through Toll-like receptors (TLRs). This form of Kupffer cell activation is considered the classic pathway of Kupffer cell activation into so-called M1 proinflammatory macrophages [14]. TLRs recognize multiple highly conserved pathogen-associated molecular patterns (PAMPs) and damage-associated molecular pathways (DAMPs). The most common pathway of Kupffer cell activation is through activation by LPS or Gram-negative bacterial endotoxin [13,15-21]. LPS binds to the acute-phase protein LPS-binding protein, enhancing interaction with the TLR4-CD14-MD2 receptor complex [22]. This interaction results in the recruitment of the adaptor molecules MyD88 and TRIF, which activate further downstream signaling cascades. The MyD88 signaling pathway is shared by all 13 members of the TLR family except for TLR3 [21]. Gram-positive bacteria interact with Kupffer cells through recognition of peptidoglycans and lipoproteins by the TLR2-TLR6 heterodimer complex $[21,23]$. Various other ligands such as viral RNA and necrotic cells have been identified interacting with specific members of the TLR family. The role of complement receptors binding $\mathrm{C} 3 \mathrm{a}$ and $\mathrm{C} 5 \mathrm{a}$ has also been established in Kupffer cell activation [12]. Recently, a new mechanism of Kupffer cell activation by hydrogen peroxide was proposed [24].

\section{Effects of classic Kupffer cell activation}

Upon activation, Kupffer cells produce a great variety of inflammatory mediators such as cytokines, chemokines, oxygen-derived free radicals, eicosanoids, and lysosomal and proteolytic enzymes $[10,12,13,18]$. The massive release of local proinflammatory cytokines such as interleukin (IL)-1, IL-6, IL-17, IL-18, and tumor necrosis factor-alpha (TNF $\alpha$ ) and the release of anti-inflammatory cytokines such as IL-4, IL-10, and IL-13 are considered causative in the subsequent development of SIRS and 
compensatory anti-inflammatory response syndrome (CARS) in acute and acute-on-chronic liver failure because of the overflow of these cytokines into the systemic circulation [25]. Among the proinflammatory cytokines, TNF $\alpha$ has been most intensively studied since it is first released and correlates well with the overall severity of liver injury [26]. Cytokine release by Kupffer cells induces important leukocyte recruitment within the liver microvasculature and parenchyma. This is mediated in part by production of chemoattractants such as IL- 8 and by expression of adhesion molecules such as ICAM-1 (intracellular adhesion molecule-1) and VCAM-1 (vascular cell adhesion molecule-1) on sinusoidal endothelial cells in response to liver injury [27]. This further leads to the production of oxidative stress and proteolytic enzymes, enhancing hepatocyte apoptosis and necrosis in liver disease. Kupffer cells are also responsible for the transformation of quiescent stellate cells into activated myofibroblasts, which drive the intrahepatic microcirculation. Furthermore, activated Kupffer cells produce vasoactive substances such as endothelin-1 (ET-1), thromboxane $A_{2}$, nitric oxide (NO), and prostaglandins, thereby establishing a direct link between immune activation and hepatic microcirculatory dysfunction [28]. Further evidence for this link is provided by a recent study demonstrating increases in portal hypertension in response to intraperitoneal LPS injection in rats [29].

\section{Alternative activation of Kupffer cells}

On the other hand, Kupffer cells can be alternatively activated by cytokines such as IL-4 and IL-10, which are produced by Th2 cells and other innate immune cells such as basophils. Upon alternative activation, they further differentiate into M2 phenotype macrophages [30]. These M2-type macrophages exert mainly anti-inflammatory effects through mediators such as transforming growth factor-beta [31].

\section{Mechanisms of innate immune dysfunction in acute-on- chronic liver failure}

The mechanisms of innate immune dysfunction in liver cirrhosis and alcoholism are numerous. First, Kupffer cells are bypassed through multiple intra- and extrahepatic shunts in cirrhosis. Second, decreased liver protein synthesis generates defects in complement production, resulting in reduced opsonization capacity in chronic liver disease. Additionally, deficiency of albumin in patients with cirrhosis is common. Albumin is known to have important detoxifying qualities such as scavenging free radicals and LPSs [10]. Third, in cirrhosis, there is evidence for a dysfunctional and hyporesponsive state of the innate immune system, a phenomenon that is known as immune paralysis [10,32]. This was also recently revealed in patients with ACLF [33]. The phenomenon of immune paralysis has been illustrated in the 2007 study of Lin and colleagues [32]: patients with Child-Pugh class $\mathrm{C}$ cirrhosis were shown to suffer from downregulation of HLA-DR expression, directly hampering the mononuclear cell antigen-presenting capacity. On the other hand, the 2006 study by Tazi and colleagues [34] revealed an increased TNF $\alpha$ production after stimulation of monocytes by LPS in patients with advanced cirrhosis. Interestingly, two other previously mentioned studies obtained opposite results in their patient groups, so these findings remain a matter of debate $[32,33]$. A similar debate regards the phagocytic capacity of neutrophils in liver disease. Some studies suggested increased radical and elastase production in response to bacterial challenge as well as increased phagocytosis in portal hypertensive rats [35-37]. Other studies demonstrated phagocytic capacity impairment in patients with alcoholic cirrhosis [38]. Globally, experimental results point toward an overall activated state of the innate immune system in chronic liver disease and an overproduction of harmful substances such as free radicals and liver parenchymal injury as a consequence. This has been nicely illustrated by the use of gadolinium chloride in animal trials, depleting the liver of Kupffer cells. Kupffer cell-depleted rats showed substantially less liver damage after partial liver resection, LPS challenge, and alcohol- and acetaminophen-induced liver injury [15,39-41]. Moreover, TNF $\alpha$ levels have been shown to be significantly elevated in patients with advanced cirrhosis, further revealing the activated state of the immune system [33]. On the other hand, the activated immune cells appear to be dysfunctional, paralyzed, and energy-depleted, making patients susceptible to infections, as demonstrated by clinical data. These findings seem to be exacerbated in the context of ACLF, resulting in an exaggerated SIRS and a defective CARS, a phenomenon known in the literature as immunological dissonance [25,33]. The additional adverse effects of alcohol on immune function, especially on TLRs and cytokines, have been extensively studied [18-20,22, 42-44]. However, this topic is beyond the scope of our review.

\section{Role of natural killer cells and natural killer T cells}

Recently, interest has arisen for other components of the innate immune system: the natural killer (NK) cells and the NK T cells. Although their role in ACLF has not yet been clearly elucidated, they obviously play an important role in many experimental models of liver injury, such as alcoholic liver disease, viral hepatitis, and autoimmune liver disease [45]. Furthermore, both NK and NK T cells are activated by bacterial toxins and bacterial superantigens and display hepatotoxicity through secretion of proinflammatory mediators such as TNF $\alpha$. However, 
Table 1. Severe inflammatory response syndrome is diagnosed if two or more of these criteria are fulfilled

Body temperature of greater than $38.5^{\circ} \mathrm{C}$ or less than $35^{\circ} \mathrm{C}$

Heart rate of greater than 90 beats per minute

Respiratory rate of greater than 20 breaths per minute or arterial partial pressure of carbon dioxide $\left(\mathrm{PaCO}_{2}\right)$ of less than $32 \mathrm{~mm} \mathrm{Hg}$

White blood cell count of greater than 12,000 cells $/ \mathrm{mm}^{3}$ or less than 4,000 cells $/ \mathrm{mm}^{3}$ or greater than $10 \%$ immature forms

anti-inflammatory markers, such as interferon-gamma, also are expressed by NK cells upon activation [46]. Future research will need to reveal the role of NK cells in the specific context of ACLF.

\section{Innate immune dysfunction in acute-on-chronic liver failure on the clinical level}

The presence of innate immune dysfunction in ACLF can be deducted from several observations in the context of ACLF, chronic liver disease, and alcoholism. The first evidence comes from clinical observations: infection is the reason for hospital admission in $15 \%$ to $35 \%$ of patients with cirrhosis, and $15 \%$ to $35 \%$ of the patients develop nosocomial infections in comparison with $5 \%$ to $7 \%$ in the general population [10]. Also, roughly one third of patients with advanced cirrhosis and culture-negative ascites exhibit bacterial DNA in circulation, which is closely correlated to the presence of intrahepatic and systemic endothelial dysfunction $[47,48]$. Furthermore, a large majority of patients with ACLF display sepsis-like characteristics such as the SIRS (Table 1) [3].

\section{Therapeutic strategies}

Many strategies have been attempted, with variable success, to modify or attenuate the immune response in acute, chronic, or acute-on-chronic liver disease. The application of corticosteroids in severe acute alcoholic hepatitis is well established [49]. Recently, more evidence has been generated regarding the beneficial effects of pentoxifylline, an inhibitor of TNF $\alpha$, in the treatment of not only severe alcoholic hepatitis but also advanced cirrhosis [50,51]. The beneficial effect of TNF $\alpha$ monoclonal antibodies in severe alcoholic hepatitis is still controversial because, in one study, this was associated with higher infection and mortality rates [52]. Currently, a lot of scientific effort is put into targeting of innate immunity with TLR agonists and antagonists, but it is still unclear whether this is beneficial in the treatment of patients with liver disease [53].

\section{Intestinal bacterial translocation}

Definition and prevalence of intestinal bacterial translocation

Bacterial translocation is defined as the migration of viable microorganisms from the gut lumen to the mesenteric lymph nodes (MLNs) or extra-intestinal sites [54]. It seems to be of importance in cirrhosis and ACLF for two reasons. First, in patients with cirrhosis, bacterial translocation from the gut is a well-known source of lifethreatening infection, such as spontaneous bacterial peritonitis. This represents an acute event in chronic liver disease, which in some patients results in ACLF. Second, bacterial translocation is thought to induce and perpetuate the previously mentioned activated state of the innate immune system [55]. Bacterial translocation has proven to be increased in experimental animal models of cirrhosis or portal hypertension and in human disease [47,56-60]. Bacterial translocation has been demonstrated especially by removal and culture of MLNs. Recently, bacterial DNA measurement in blood samples has proven to be a reliable, non-invasive, and probably more sensitive surrogate marker for translocation of viable bacteria in cirrhosis [48,60]. The prevalence of bacterial translocation is closely related to the severity of liver disease. For instance, bacterial translocation to MLNs has been demonstrated uniquely in animal models of cirrhosis in the presence of ascites [58]. Furthermore, in a large study in humans, only the ChildPugh class and not the degree of portal hypertension was a predictive factor for the prevalence of bacterial translocation, suggesting that liver dysfunction might be more crucial in the development of bacterial translocation than portal hypertension in itself [57]. In that study, the prevalence of bacterial translocation increased according to the Child-Pugh classification: $3.4 \%$ in Child A, $8.1 \%$ in Child B, and $30.8 \%$ in Child C cirrhotic patients. However, this concept was challenged in two earlier experimental studies, in which acute (2-day) portal hypertension induced bacterial translocation in partial portal vein-ligated rats without liver disease [56]. In another study, bacterial translocation could also be demonstrated in rats with chronic portal hypertension, induced by means of partial portal vein ligation [59]. Moreover, it has been demonstrated that a second, acute injury to the system, such as hemorrhagic shock, further increases bacterial translocation from the gut, indicating its potentially important role in ACLF [59,61]. The presence of bacterial DNA in patients with cirrhosis proved, in a recent study, to be closely correlated to systemic and intrahepatic microcirculatory abnormalities [47]. This confirms once more the close link between circulatory dysfunction, immune dysfunction, and bacterial translocation in liver disease. 


\section{Mechanisms of bacterial translocation}

Bacterial translocation originates from a large variety of dysfunctions within the gut-liver axis. Three key elements are recognized: changes in intestinal microflora, changes in intestinal permeability, and inadequate response of the gut immune system [55].

\section{Changes in intestinal microflora}

The microorganisms that are most frequently involved in bacterial translocation in humans are aerobic bacteria such as Escherichia coli, Klebsiella spp., Staphylococcus aureus, and Enterococcus [48]. In normal intestines, anaerobic bacteria, which rarely translocate, outnumber aerobic bacteria by $100: 1$ to $1,000: 1$ [62]. Anaerobic bacteria are known to prevent aerobic bacterial overgrowth. In patients with cirrhosis, bacterial overgrowth and changes in intestinal bacterial composition which were attributed largely to alterations in short-bowel motility and intestinal transit time have been documented $[63,64]$. This offers, in part, an explanation why aerobic bacteria are capable of translocating from the intestine in patients with cirrhosis.

\section{Increased intestinal permeability}

Another explanation for bacterial translocation is that patients with cirrhosis display increased intestinal permeability. In normal circumstances, intestinal permeability to water-soluble molecules is determined by the presence of tight junctions between intestinal epithelial cells [65]. These tight junctions restrict diffusion of molecules up to $2 \mathrm{kDa}$ through the paracellular space, preventing migration of bacteria but also of bacterial endotoxins through the intestinal epithelium [55]. In patients with cirrhosis, permeability was shown to be increased [66]. This is easy to conceive given the major morphological changes that occur in the intestinal epithelium in rat models of experimental cirrhosis. For instance, the viability of enterocytes in these rats was decreased, the villus fraction of enterocytes was heavily reduced, and (importantly) the cytoskeleton displays important morphological changes in cirrhosis [67]. The increases of intestinal permeability in cirrhosis have been attributed to the role of oxygen free radical damage, venous congestion, $\mathrm{NO}$, and the direct effects of alcohol on the gut barrier [22,47,61,67].

\section{Innate immune dysfunction in the gut}

Finally, in normal circumstances, translocated microorganisms are easily phagocytized and removed by intestinal macrophages. However, in chronic liver disease, this bactericidal capacity is reduced, as discussed in the above sections.

\section{Therapeutic strategies}

Strategies to prevent translocation of aerobic bacteria from the gut have been successfully applied in patients with cirrhosis. For instance, antibiotics such as norfloxacin, known to selectively decontaminate the gut from Gram-negative bacteria, are used in variceal bleeding and the prevention of spontaneous bacterial peritonitis [68]. Furthermore, Tazi and colleagues [69] demonstrated that the hyperdynamic circulatory syndrome could be ameliorated by norfloxacin. Of interest, in a recent study in 30 patients with decompensated cirrhosis, a significant reduction of systemic and splanchnic plasma endotoxin levels but also a significant reduction of hepatic venous pressure gradient (HVPG) values were seen after intestinal decontamination therapy with rifaximin [70]. Other strategies such as probiotics and intestinal prokinetics such as propranolol were successful in animal trials but need further validation in humans [71].

\section{Circulatory dysfunction}

Innate immune dysfunction and bacterial translocation in the onset of ACLF result in major alterations on the macrocirculatory and intrahepatic microcirculatory levels (Figure 3).

\section{Macrocirculatory level}

On the macrocirculatory level, patients with ACLF display an aggravation of the hyperdynamic circulation, which is already present in advanced stages of compensated cirrhosis. Cardiac output is increased and peripheral circulation is dilated and hyporesponsive. Mean arterial blood pressure is decreased. On the splanchnic level, there is important arterial vasodilatation and portal hypertension, resulting in renal hypoperfusion. This further leads to water and sodium retention by activation of the renin-angiotensin II-aldosterone pathway and secretion of antidiuretic hormone [2]. In patients with cirrhosis, two important mechanisms have been recognized in the development and aggravation of portal hypertension. First, there is an increase of intrahepatic vascular resistance (IHVR), which can be attributed largely to alterations on the sinusoidal level [26]. Second, increased portal venous flow results from splanchnic hyperemia because of splanchnic arterial vasodilatation. Multiple factors have been implicated in these hemodynamic alterations.

\section{Nitric oxide}

An important role for NO is suggested on the peripheral as well as on the splanchnic level. NO is produced by two enzymes: one is an inducible isoform, iNOS, and the other is an endothelial constitutive isoform, eNOS. The latter proved to be the more important source of mesenteric artery NO overexpression in portal hypertension [72-74]. This upregulation of eNOS is thought to originate from shear stress increases related to increased splanchnic inflow [75]. Of interest in ACLF, an 


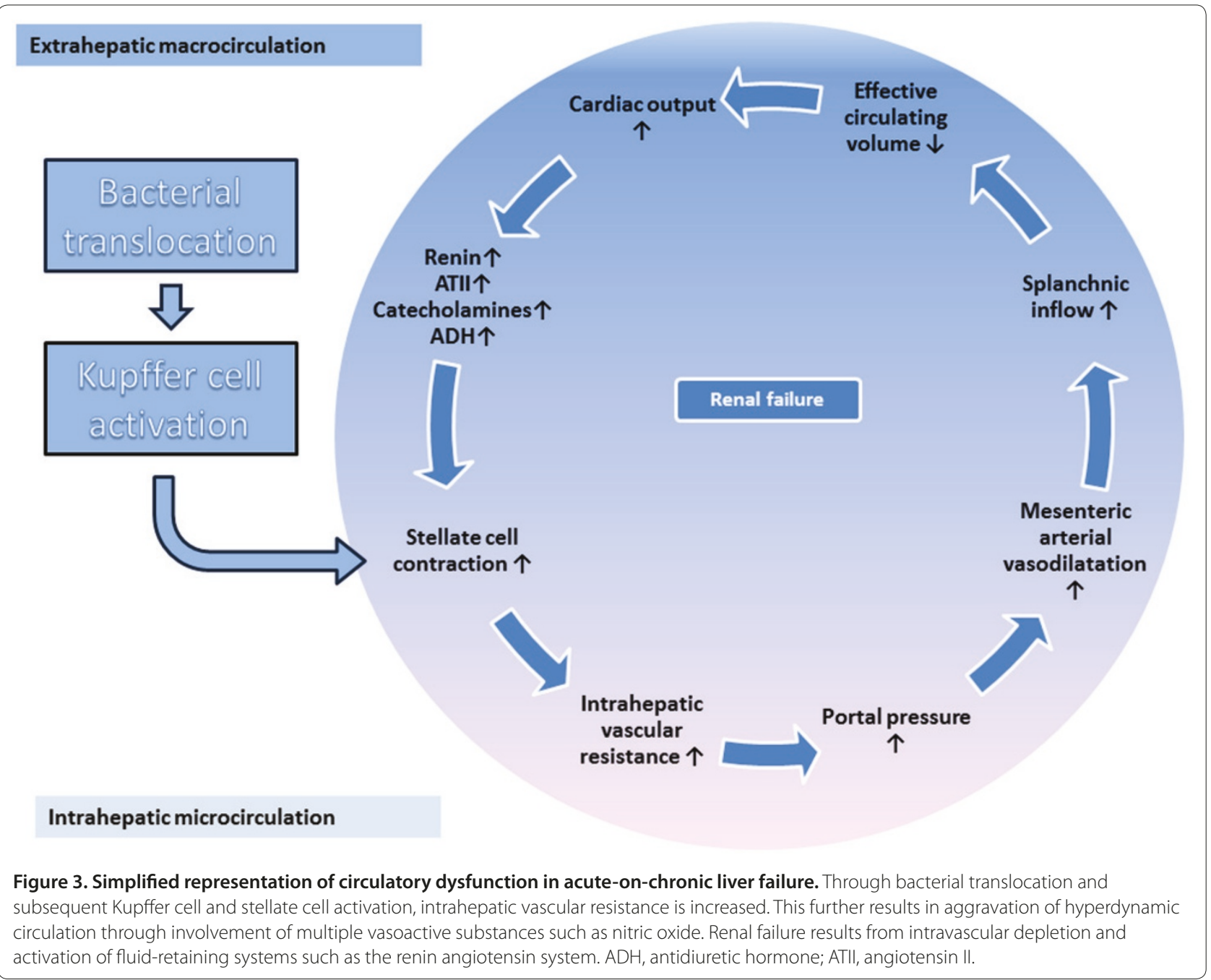

upregulation of eNOS was seen in rats with bacterial translocation, correlating to circulating TNF $\alpha$ levels and severity of intrahepatic microcirculatory dysfunction [76].

\section{Microcirculatory level: stellate cells}

On the hepatic level, IHVR has proven to be partly static and partly dynamic [77]. This can be attributed to the microcirculatory system within the liver sinusoids. The presence of vascular thrombi, collagen deposits within the space of Disse, and nodular regeneration explain the static component in IHVR. However, portal hypertension can be partially reversed by use of vasoactive substances in liver perfusion studies [78-80]. This represents a dynamic and modifiable part of portal hypertension. The contractile elements within the hepatic microcirculation have proven to be the stellate cells. This has been demonstrated in vitro, in stellate cell gel contraction models, and in in vivo microscopy studies. Their distribution along the perisinusoidal space presents them with optimal sinusoidal constriction capacity. In normal liver, stellate cells are quiescent fat-storing cells. However, in the presence of liver injury, they become activated and proliferate into hepatic myofibroblasts. These myofibroblasts develop contractile properties through cytoplasmic processes and acquisition of multiple smooth muscle proteins [81]. Hepatic stellate cell contraction is mediated through both $\mathrm{Ca}^{2+}$-dependent and independent pathways [82]. Also, the role of sinusoidal endothelial cells in microvascular dysfunction in liver injury has been well established. Next to the production of vasoactive mediators such as NO and ET-1, sinusoidal endothelial cells are known to exert proinflammatory, proadhesive, and procoagulant properties upon activation [26]. Through close intercellular interaction with Kupffer cells and stellate cells, this vasomotor dysfunction is aggravated, probably promoting hepatocellular injury and a portal pressure increase in ACLF. 
Table 2. Vasoconstrictors and vasodilators affecting hepatic microcirculation $[77,79,80,86,91-95]$

\begin{tabular}{llll}
\hline Vasoconstrictors & Related therapy & Vasodilators & Related therapy \\
\hline Endothelin-1 & Bosentan and tezosentan & Nitric oxide (NO) & $\begin{array}{l}\text { Isorbide-5-mononitrate, nitroglycerin, } \\
\text { NO-ursodeoxycholic acid, statins, and } \\
\text { nitroflurbiprofen }\end{array}$ \\
Leukotrienes & Montelukast & Carbon monoxide \\
Angiotensin-II & $\begin{array}{l}\text { Angiotensin-converting enzyme } \\
\text { inhibitors and sartans }\end{array}$ & Prostaglandins \\
Catecholamines & Beta-blockers and prazosin & $\mathrm{H}_{2} \mathrm{~S}$ \\
Thromboxane $\mathrm{A}_{2}$ & Nitroflurbiprofen & \\
\hline
\end{tabular}

\section{Endothelin-1}

Many authors have concluded that the dynamic component of microcirculatory dysfunction within the liver must be due to overproduction or hyper-responsiveness to vasoconstrictors or to underproduction or hyporesponsiveness to vasodilators or to both. Many important vasoactive substances have since been identified (Table 2). The most important of these mediators are ET-1, NO, and carbon monoxide (CO). ET-1 is apparently the most important hepatic vasoconstrictor, directly interacting with the production of vasodilative substances such as NO and CO [26]. ET-1 is produced within liver sinusoidal endothelial cells, Kupffer cells, and stellate cells [28]. Increased plasma concentrations of ET-1 have been demonstrated in different disease states, such as hemorrhagic shock, endotoxinemia, and polymicrobial sepsis [78,83]. Furthermore, chronic liver exposure to endotoxins enhances ET-1-mediated microcirculatory disturbances in experimental rat models [84]. This increased sensitivity is mediated through alterations in ET-1 receptor expression profiles on both sinusoidal endothelial cells and hepatic stellate cells [26]. ET-1 exerts its effect through $\mathrm{ET}_{\mathrm{A}}, \mathrm{ET}_{\mathrm{B} 1}$, and $\mathrm{ET}_{\mathrm{B} 2}$ receptors. $\mathrm{ET}_{\mathrm{A}}$ receptors, mediating vasoconstriction within the liver vasculature, have been shown to be downregulated in conditions of endotoxinemia and ischemia-reperfusion injury [83]. However, in experimental polymicrobial sepsis in rats, $\mathrm{ET}_{\mathrm{B} 2}$ receptor upregulation proves to be more important than $\mathrm{ET}_{\mathrm{A}}$ receptor downregulation, resulting in an overall exaggerated vasoconstrictive response to ET-1 $[78,83]$. Stellate cell-mediated vasoconstriction appears to be a crucial element in the development of ACLF. First, it contributes to sinusoidal perfusion failure, liver necrosis, and subsequent liver failure by impairing nutrient and oxygen supply to hepatocytes. Second, it aggravates portal hypertension and circulatory dysfunction and gives rise to typical vascular complications of acute-on-chronic liver disease, such as variceal bleeding. These findings on circulatory dysfunction offer, in part, an explanation for the development of ACLF in cirrhotic patients confronted with infection or gastrointestinal bleeding.

\section{Adrenal insufficiency}

Finally, in cirrhotic patients with renal failure or sepsis, a high incidence of adrenal insufficiency was found (range of $40 \%$ and $75 \%$ ). Adrenal dysfunction seemed to be closely related to hemodynamic changes and mortality. The importance of this phenomenon and its potential therapeutic implications needs further validation [85].

\section{Therapeutic strategies}

ET-1 has been targeted in the experimental treatment of portal hypertension in multiple animal trials. Bosentan, for instance, a mixed $\mathrm{ET}_{\mathrm{A}}$ and $\mathrm{ET}_{\mathrm{B}}$ receptor antagonist, has proven to be beneficial in the treatment of portal hypertension and portal hypertension-related complications such as variceal bleeding [86-88]. However, a recent European post-marketing study on the safety profile of bosentan in the treatment of pulmonary hypertension in 4,994 patients demonstrated elevated aminotransferases in $7.6 \%$ of patients over a period of 3,416 patient-years [89]. However, this toxic effect proved to be early and mostly mild and transient. Of interest, in two studies, bosentan was safely administered to 93 Child A cirrhotic patients suffering from portopulmonary hypertension $[89,90]$. Tezosentan, also a specific non-selective ET receptor antagonist, is also shown to limit liver injury in endotoxin-challenged cirrhotic rats [91]. In this respect, strategies to increase intrahepatic NO concentrations have been extensively studied. Replenishment of the defective eNOS enzyme has been obtained by NOS gene transfer in cirrhotic rats, attenuating portal hypertension [92]. Liver-directed NO donors have also been used with positive results in cirrhotic animal trials such as NOreleasing bile acids [93]. However, a recent randomized double-blind trial in humans failed to demonstrate portal pressure reduction in cirrhosis by means of NCX-1000, an NO-releasing derivative of ursodeoxycholic acid [94]. Also, statins are known to decrease the intrahepatic vascular tone in humans through an increase of hepatic NO production [95]. This is particularly important in ACLF since statins have been shown to improve outcome in sepsis, severe sepsis, and fatal sepsis [96,97]. Nitroflurbiprofen, an NO-releasing cyclooxygenase inhibitor, 
was also proven to be beneficial in rat models of cirrhotic portal hypertension [80]. Studies in patients on this topic are lacking. Furthermore, experimental studies examining the beneficial effects in the specific context of ACLF need to be evaluated. The use of hydrocortisone in cirrhotic patients with documented adrenal insufficiency and septic shock is also under investigation. In a recent study by Arabi and colleagues [98] (2010), the administration of hydrocortisone in these patients resulted in higher shock reversal rates and less vasopressor use but significantly more gastrointestinal bleeding and ultimately comparable survival rates in comparison with the placebo-treated group.

\section{Conclusions}

ACLF is an important clinical challenge since it remains a highly prevalent, life-threatening disease with few therapeutic options at present. Treatment options are currently limited to supportive measures. However, ACLF has proven to be a potentially reversible complication of chronic liver disease. This emphasizes the need for a guided therapeutic approach, shifting the downward spiral seen in ACLF toward hepatic recompensation. The application of liver support devices for this indication has been disappointing, although further analysis in certain subgroups of patients might be warranted $[99,100]$. In recent years, knowledge regarding the pathophysiology of ACLF has largely increased. All research has pointed toward the interaction between innate immune dysfunction, bacterial translocation from the gut, and (micro) circulatory dysfunction as key players. This has resulted in several treatment modalities proven to be beneficial in animal or in vitro studies of liver disease. However, clinical studies in humans, especially in ACLF, are lacking.

A second strategy to prevent ACLF-related death might lie in the early recognition of this syndrome. For example, since the development of ACLF coincides with the development of multi-organ failure, early recognition of kidney injury by use of biomarkers of renal function could be useful in predicting the development of ACLF in cirrhotic patients confronted with acute disease [49]. It is likely that combining an early recognition of the syndrome with a more pathophysiology-guided therapeutic approach will result in better survival rates of patients with ACLF, also reducing the need for liver grafts as an ultimate salvage therapy.

\section{Abbreviations}

ACLF, acute-on-chronic liver failure; CARS, compensatory anti-inflammatory response syndrome; $\mathrm{CHD}$, chronic hepatic decompensation; $\mathrm{CO}$, carbon monoxide; eNOS, endothelial nitric oxide synthase; ET-1, endothelin-1; IHVR, intrahepatic vascular resistance; IL, interleukin; LPS, lipopolysaccharide; MLN, mesenteric lymph node; NK, natural killer; NO, nitric oxide; NOS, nitric oxide synthase; SIRS, severe inflammatory response syndrome; TLR, Toll-like receptor; TNFa, tumor necrosis factor-alpha.
Competing interests

The authors declare that they have no competing interests.

\section{Acknowledgments}

LV is an aspirant-researcher and was granted a PhD fellowship by the Fund for Scientific Research - Flanders (Aspirant-mandaat - FWO Vlaanderen). $W L$ and FN are senior clinical investigators for the Fund for Scientific Research Flanders (Fundamenteel klinisch mandaat - FWO Vlaanderen).

Published: 25 October 2011

\section{References}

1. Stange J, Ramlow W, Mitzner S, Schmidt R, Klinkmann H: Dialysis against a recycled albumin solution enables the removal of albumin-bound toxins. Artif Organs 1993, 17:809-813.

2. Jalan R, Williams R: Acute-on-chronic liver failure: pathophysiological basis of therapeutic options. Blood Purif 2002, 20:252-261.

3. Katoonizadeh A, Laleman W, Verslype C, Wilmer A, Maleux G, Roskams T, Nevens F: Early features of acute-on-chronic alcoholic liver failure: a prospective cohort study. Gut 2010, 59:1561-1569.

4. Hassanein TI, Tofteng F, Brown RS Jr., McGuire B, Lynch P, Mehta R, Larsen FS, Gornbein J, Stange J, Blei AT: Randomized controlled study of extracorporeal albumin dialysis for hepatic encephalopathy in advanced cirrhosis. Hepatology 2007, 46:1853-1862.

5. Flink HJ, Sprengers D, Hansen BE, van Zonneveld M, de Man RA, Schalm SW, Janssen HL; HBV 99-01 Study Group: Flares in chronic hepatitis B patients induced by the host or the virus? Relation to treatment response during Peg-interferon \{alpha\}-2b therapy. Gut 2005, 54:1604-1609.

6. Lee KH, Lee MK, Sutedja DS, Lim SG: Outcome from molecular adsorbent recycling system (MARS) liver dialysis following drug-induced liver failure. Liver Int 2005, 25:973-977.

7. Hamid SS, Atiq M, Shehzad F, Yasmeen A, Nissa T, Salam A, Siddiqui A, Jafri W: Hepatitis $E$ virus superinfection in patients with chronic liver disease. Hepatology 2002, 36:474-478.

8. Sarin SK, Kumar A, Almeida JA, Chawla YK, Fan ST, Garg H, de Silva HJ, Hamid SS, Jalan R, Komolmit P, Lau GK, Liu Q, Madan K, Mohamed R, Ning Q, Rahman S, Rastogi A, Riordan SM, Sakhuja P, Samuel D, Shah S, Sharma BC, Sharma P, Takikawa Y, Thapa BR, Wai CT, Yuen MF: Acute-on-chronic liver failure: consensus recommendations of the Asian Pacific Association for the study of the liver (APASL). Hepatol Int 2009, 3:269-282.

9. Sen S, Williams R, Jalan R: The pathophysiological basis of acute-on-chronic liver failure. Liver 2002, 22:5-13.

10. Leber B, Mayrhauser U, Rybczynski M, Stadlbauer V: Innate immune dysfunction in acute and chronic liver disease. Wien Klin Wochenschr 2009, 121:732-744.

11. Cazzaniga M, Dionigi E, Gobbo G, Fioretti A, Monti V, Salerno F: The systemic inflammatory response syndrome in cirrhotic patients: relationship with their in-hospital outcome. J Hepatol 2009, 51:475-482.

12. Bilzer M, Roggel F, Gerbes AL: Role of Kupffer cells in host defense and liver disease. Liver Int 2006, 26:1175-1186.

13. Kolios $G$, Valatas $V$, Kouroumalis E: Role of Kupffer cells in the pathogenesis of liver disease. World J Gastroenterol 2006, 12:7413-7420.

14. Heymann F, Trautwein C, Tacke F: Monocytes and macrophages as cellular targets in liver fibrosis. Inflamm Allergy Drug Targets 2009, 8:307-318.

15. Prins HA, Meijer C, Boelens PG, Diks J, Holtz R, Masson S, Daveau M, Meijer S, Scotté M, van Leeuwen PA: Kupffer cell-depleted rats have a diminished acute-phase response following major liver resection. Shock 2004, 21:561-565.

16. Sakamoto S, Okanoue T, Itoh Y, Nakagawa Y, Nakamura H, Morita A, Daimon Y, Sakamoto K, Yoshida N, Yoshikawa T, Kashima K: Involvement of Kupffer cells in the interaction between neutrophils and sinusoidal endothelial cells in rats. Shock 2002, 18:152-157.

17. Jaeschke H, Farhood A: Kupffer cell activation after no-flow ischemia versus hemorrhagic shock. Free Radic Biol Med 2002, 33:210-219.

18. Pimentel-Nunes P, Roncon-Albuquerque R Jr., Gonçalves N, FernandesCerqueira C, Cardoso H, Bastos RP, Marques M, Marques C, Alexandre Sarmento J, Costa-Santos C, Macedo G, Pestana M, Dinis-Ribeiro M, LeiteMoreira AF: Attenuation of toll-like receptor 2-mediated innate immune response in patients with alcoholic chronic liver disease. Liver Int 2010, 30:1003-1011.

19. Stadlbauer V, Shah N, de Oca Arjona MM, Mookerjee RP, Jalan R: Alcohol 
takes the toll on immune function. Liver Int 2010, 30:934-936.

20. Stadlbauer V, Mookerjee RP, Wright GA, Davies NA, Jürgens G, Hallström S, Jalan R: Role of Toll-like receptors 2,4 and 9 in mediating neutrophil dysfunction in alcoholic hepatitis. Am J Physiol Gastroinstest Liver Physhiol 2009, 296:G15-G22.

21. Seki E, Brenner DA: Toll-like receptors and adaptor molecules in liver disease: update. Hepatology 2008, 48:322-335.

22. Szabo G, Bala S: Alcoholic liver disease and the gut-liver axis. World J Gastroenterol 2010, 16:1321-1329.

23. Yoshimura A, Lien E, Ingalls RR, Tuomanen E, Dziarski R, Golenbock D: Cutting edge: recognition of Gram-positive bacterial cell wall components by the innate immune system occurs via Toll-like receptor 2. J Immuno/ 1999, 163:1-5.

24. Steib CJ, Bilzer M, Härtl JM, Beitinger F, Gülberg V, Göke B, Gerbes AL: Kupffer cell activation by hydrogen peroxide: a new mechanism of portal pressure increase. Shock 2010, 33:412-418.

25. Antoniades $C G$, Berry PA, Wendon JA, Vergani D: The importance of immune dysfunction in determining outcome in acute liver failure. J Hepatol 2008, 49:845-861.

26. Vollmar B, Menger MD: The hepatic microcirculation: mechanistic contributions and therapeutic targets in liver injury and repair. Physiol Rev 2009, 89:1269-1339.

27. Steinhoff G, Behrend M, Schrader B, Duijvestijn AM, Wonigeit K: Expression patterns of leukocyte adhesion ligand molecules on human liver endothelia Lack of ELAM-1 and CD62 inducibility on sinusoidal endothelia and distinct distribution of VCAM-1, ICAM-1, ICAM-2 and LFA-3. Am J Pathol 1993, 142:481-488

28. Rockey DC, Fouassier L, Chung JJ, Carayon A, Vallee P, Rey C, Housset C: Cellular localization of endothelin-1 and increased production in liver injury in the rat: potential for autocrine and paracrine effects on stellate cells. Hepatology 1998, 27:472-480.

29. Steib CJ, Hartmann AC, v Hesler C, Benesic A, Hennenberg M, Bilzer M, Gerbes AL: Intraperitoneal LPS amplifies portal hypertension in rat liver fibrosis. Lab Invest 2010, 90:1024-1032.

30. Brubaker Jo, Montaner LJ: Role of interleukin-13 in innate and adaptive immunity. Cell Mol Biol 2001, 47:637-651.

31. Lee CG, Homer RJ, Zhu Z, Lanone S, Wang X, Koteliansky V, Shipley JM, Gotwals P, Noble P, Chen Q, Senior RM, Elias JA: Interleukin-13 induces tissue fibrosis by selectively stimulating and activating transforming growth factor beta. J Exp Med 2001, 194:809-821.

32. Lin CY, Tsai IF, Ho YP, Huang CT, Lin YC, Lin CJ, Tseng SC, Lin WP, Chen WT, Sheen IS: Endotoxinemia contributes to the immune paralysis in patients with cirrhosis. J Hepatol 2007, 46:816-826

33. Wasmuth $H E$, Kunz D, Yagmur E, Timmer-Stranghöner A, Vidacek D, Siewert $E$, Bach J, Geier A, Purucker EA, Gressner AM, Matern S, Lammert F: Patients with acute on chronic liver failure display 'sepsis-like' immune paralysis. $J$ Hepatol 2005, 42:195-201.

34. Tazi KA, Quioc JJ, Saada V, Bezeaud A, Lebrec D, Moreau R: Upregulation of TNF-alpha production signaling pathways in monocytes from patients with advanced cirrhosis: possible role of Akt and IRAK-M. J Hepatol 2006, 45:280-289.

35. Taïeb J, Mathurin P, Elbim C, Cluzel P, Arce-Vicioso M, Bernard B, Opolon P, Gougerot-Pocidalo MA, Poynard T, Chollet-Martin S: Blood neutrophil functions and cytokine release in severe alcoholic hepatitis: effect of corticosteroids. J Hepatol 2000, 32:579-586.

36. Stanley AJ, MacGregor IR, Dillon JF, Bouchier IA, Hayes PC: Neutrophil activation in chronic liver disease. Eur I Gastroenterol Hepatol 1996, 8:135-138.

37. Neugebauer H, Hartmann P, Krenn S, GlückT, Schölmerich J, Straub R, Wiest R: Bacterial translocation increases phagocytic activity of polymorphonuclear leucocytes in portal hypertension: priming independent of liver cirrhosis. Liver Int 2008, 28:1 149-1157.

38. Feliu E, Gougerot MA, Hakim J, Cramer E, Auclair C, Rueff B, Boivin P: Blood polymorphonuclear dysfunction in patients with alcoholic cirrhosis. Eur Clin Invest 1977, 7:571-577.

39. Abrahám S, Szabó A, Kaszaki J, Varga R, Eder K, Duda E, Lázár G, Tiszlavicz L, Boros M, Lázár G Jr.: Kupffer cell blockade improves the endotoxin-induced microcirculatory inflammatory response in obstructive jaundice. Shock 2008, 31:69-74.

40. Adachi Y, Bradford BU, Gao W, Bojes HK, Thurman RG: Inactivation of Kupffer cells prevents early alcohol-induced liver injury. Hepatology 1994,
20:453-460.

41. Michael SL, Pumford NR, Mayeux PR, Niesman MR, Hinson JA: Pretreatment of mice with macrophage inactivators decreases acetaminophen hepatotoxicity and the formation of reactive oxygen and nitrogen species. Hepatology 1999, 30:186-195.

42. Mandal P, Pritchard MT, Nagy LE: Anti-inflammatory pathways and alcoholic liver disease: Role of an adiponectin/interleukin-10/heme-oxygenase-1 pathway. World J Gastroenterol 2010, 16:1330-1336.

43. Szabo G, Mandrekar P, Girouard L, Catalano D: Regulation of human monocyte functions by acute ethanol treatment: decreased tumor necrosis factor- $\alpha$, interleukin- $1 \beta$ and elevated interleukin-10, and transforming growth factor- $\beta$ production. Alcohol Clin Exp Res 1996, 20:900-907.

44. Addolorato G, Russell M, Albano E, Haber PS, Wands JR, Leggio L: Understanding and treating patients with alcoholic cirrhosis: an update. Alcohol Clin Exp Res 2009, 33:1136-1144.

45. Notas G, Kisseleva T, Brenner D: NK and NKT cells in liver injury and fibrosis. Clin Immunol 2009, 130:16-26.

46. Suh YG, Jeong WI: Hepatic stellate cells and innate immunity in alcoholic liver disease. World J Gastroentero/ 2011, 130:16-26.

47. Bellot P, García-Pagán JC, Francés R, Abraldes JG, Navasa M, Pérez-Mateo M, Such J, Bosch J: Bacterial DNA translocation is associated with systemic circulatory abnormalities and intrahepatic endothelial dysfunction in patients with cirrhosis. Hepatology 2010, 52:2044-2052.

48. Guarner C, González-Navajas JM, Sánchez E, Soriando G, Francés R, Chiva M, Zapater P, Benlloch S, Muñoz C, Pascual S, Balanzó J, Pérez-Mateo M, Such J: The detection of bacterial DNA in blood of rats with $\mathrm{CCl}_{4}$-induced cirrhosis with ascites represents episodes of bacterial translocation. Hepatology 2006, 44:633-639.

49. Cárdenas A, Ginès P: Acute-on-chronic liver failure: the kidneys. Curr Opin Crit Care 2011, 17:184-189.

50. Lebrec D, Thabut D, Oberti F, Perarnau JM, Condat B, Barraud H, Saliba F, Carbonell N, Renard P, Ramond MJ, Moreau R, Poynard T; Pentocir Group: Pentoxifylline does not decrease short-term mortality but does reduce complications in patients with advanced cirrhosis. Gastroenterology 2010, 138:1755-1762.

51. Akriviadis E, Botla R, Briggs W, Han S, Reynolds T, Shakil O: Pentoxifylline improves short-term survival in severe acute alcoholic hepatitis: a doubleblind, placebo-controlled trial. Gastroenterology 2000, 119:1637-1648.

52. Tilg H, Jalan R, Kaser A, Davies NA, Offner FA, Hodges SJ, Ludwiczek O, Shawcross D, Zoller H, Alisa A, Mookerjee RP, Graziadei I, Datz C, Trauner M, Schuppan D, Obrist P, Vogel W, Williams R: Anti-tumor necrosis factor-alpha monoclonal antibody therapy in severe alcoholic hepatitis. $J$ Hepatol 2003 38:419-425.

53. Kanzler H, Barrat FJ, Hessel EM, Coffman RL: Therapeutic targeting of innate immunity with Toll-like receptor agonists and antagonists. Nat Med 2007, 13:552-559.

54. Garcia-Tsao G: Gut microflora in the pathogenesis of the complications of cirrhosis. Best Pract Res Clin Gastroenterol 2004, 18:353-372.

55. Wiest R, Garcia-Tsao G: Bacterial translocation in cirrhosis. Hepatology 2005 41:422-433.

56. Garcia-Tsao G, Albillos A, Barden GE, West AB: Bacterial translocation in acute and chronic portal hypertension. Hepatology 1993, 17:1081-1085.

57. Cirera I, Bauer TM, Navasa M, Vila J, Grande L, Taurá P, Fuster J, GarcíaValdecasas JC, Lacy A, Suárez MJ, Rimola A, Rodés J: Bacterial translocation of enteric organisms in patients with cirrhosis. J Hepatol 2001, 34:32-37.

58. Garcia-Tsao G, Lee FY, Barden GE, Cartun R, West AB: Bacterial translocation to mesenteric lymph nodes is increased in cirrhotic rats with ascites. Gastroenterology 1995, 108:1835-1841.

59. Sorell WT, Quigley EM, Jin G, Johnson TJ, Rikkers LF: Bacterial translocation in the portal-hypertensive rat: studies in basal condition and on exposure to hemorrhagic shock. Gastroenterology 1993, 104:1722-1726.

60. Such J, Francés R, Muñoz C, Zapater P, Casellas JA, Cifuentes A, RodríguezValera F, Pascual S, Sola-Vera J, Carnicer F, Uceda F, Palazón JM, Pérez-Mateo M: Detection and identification of bacterial DNA in patients with cirrhosis and culture-negative, nonneutrocytic ascites. Hepatology 2002, 36:135-141.

61. Wang W, Smail N, Wang P, Chaudry IH: Increased gut permeability after hemorrhage is associated with upregulation of local and systemic IL-6. J Surg Res 1998, 79:39-46.

62. Steffen EK, Berg RD, Deitch EA: Comparison of translocation rates of various indigenous bacteria from the gastrointestinal tract to the mesenteric 
lymph node. J Infect Dis 1988, 1574:1032-1038

63. Bauer TM, Schwacha H, Steinbrückner B, Brinkmann FE, Ditzen AK, Aponte JJ, Pelz K, Berger D, Kist M, Blum HE: Small intestinal overgrowth and bacterial translocation in human cirrhosis is associated with systemic endotoxinemia. Am J Gastroenterol 2002, 97:2364-2370

64. Chang $\mathrm{CS}$, Chen GH, Lien HC, Yeh HZ: Small intestine dysmotility and bacterial overgrowth in cirrhotic patients with spontaneous bacterial peritonitis. Hepatology 1998, 28:1187-1190.

65. Teshima CW, Meddings JB: The measurement and clinical significance of intestinal permeability. Current Gastroenterol Rep 2008, 10:443-449.

66. Pascual S, Such J, Esteban A, Zapater P, Casellas JA, Aparicio JR, Girona E, Gutiérrez A, Carnices F, Palazón JM, Sola-Vera J, Pérez-Mateo M: Intestinal permeability is increased in patients with advanced cirrhosis. Hepatogastroenterology 2003, 50:1482-1486.

67. Ramachandran A, Prabhu R, Thomas S, Reddy JB, Pulimood A, Balasubramanian KA: Intestinal mucosal alterations in experimental cirrhosis in the rat: role of oxygen free radicals. Hepatology 2002, 35:622-629.

68. Wong F, Bernardi M, Balk R, Christman B, Moreau R, Garcia-Tsao G, Patch D, Soriano G, Hoefs J, Navasa M; International Ascites Club: Sepsis in cirrhosis: report on the $7^{\text {th }}$ meeting of the international ascites club. Gut 2005, 654:718-725.

69. Tazi KA, Moreau R, Hervé P, Dauvergne A, Cazals-Hatem D, Bert F, Poirel O, Rabiller A, Lebrec D: Norfloxacin reduces aortic NO synthases and proinflammatory cytokine up-regulation in cirrhotic rats: role of Akt signaling. Gastroenterology 2005, 129:303-314.

70. Vlachogiannakos J, Saveriadis AS, Viazis N, Theodoropoulos I, Foudoulis K, Manolakopoulos S, Raptis S, Karamanolis DG: Intestinal decontamination improves liver haemodynamics in patients with alcohol-related decompensated cirrhosis. Aliment Pharmacol Ther 2009, 29:992-999.

71. Cesaro C, Tiso A, Del Prete A, Cariello R, Tuccillo C, Cotticelli G, Del Vecchio Blanco C, Loguercio C: Gut microbiota and probiotics in chronic liver diseases. Dig Liver Dis 2011, 43:431-438.

72. Martin PY, Xu DL, Niederberger M, Weigert A, Tsai P, St John J, Gines P, Schrie RW: Upregulation of endothelial constitutive NOS: a major role in the increased NO production in cirrhotic rats. Am J Physiol 1996, 270:494-499.

73. Fernández M, García-Pagán JC, Casadevall M, Bernadich C, Piera C, Whittle BJ, Piqué JM, Bosch J, Rodés J: Evidence against a role for inducible nitric oxide synthase in the hyperdynamic circulation of portal hypertensive rats. Gastroenterology 1995, 108:1487-1495.

74. Cahill PA, Redmond EM, Hodges R, Zhang S, Sitzmann JV: Increased endothelial nitric oxide synthase activity in the hyperemic vessels of portal hypertensive rats. J Hepatol 1996, 25:370-378.

75. Tazi KA, Barrière E, Moreau R, Heller J, Sogni P, Pateron D, Poirel O, Lebrec D: Role of shear stress in aortic eNOS up-regulation in rats with biliary cirrhosis. Gastroenterology 2002, 122:1869-1877.

76. Wiest R, Das S, Cadelina G, Garcia-Tsao G, Milstien S, Groszmann RJ: Bacterial translocation in cirrhotic rats stimulates eNOS-derived NO production and impairs mesenteric vascular contractility. J Clin Invest 1999, 104:1223-1233.

77. Laleman W, Landeghem L, Wilmer A, Fevery J, Nevens F: Portal hypertension: from pathophysiology to clinical practice. Liver Int 2005, 25:1079-1090.

78. Pannen BH, Bauer M, Nöldge-Schomburg GF, Zhang JX, Robotham JL, Clemens MG, Geiger KK: Regulation of hepatic blood flow during resuscitation from hemorrhagic shock: role of $\mathrm{NO}$ and endothelins. Am J Physiol 1997, 272:2736-2745.

79. Steib CJ, Bilzer M, op den Winkel M, Pfeiler S, Hartmann AC, Hennenberg M, Göke B, Gerbes AL: Treatment with the leukotriene inhibitor montelukast for 10 days attenuates portal hypertension in rat liver cirrhosis. Hepatology 2010, 51:2086-2096

80. Laleman W, Van Landeghem L, Van der Elst I, Zeegers M, Fevery J, Nevens F: Nitroflurbiprofen, a nitric oxide-releasing cyclooxygenase inhibitor, improves cirrhotic portal hypertension in rats. Gastroenterology 2007, 132:709-719.

81. Rockey DC: Hepatic blood flow regulation by stellate cells in normal and injured liver. Semin Liver Dis 2001, 21:337-349.

82. Laleman W, Van Landeghem L, Severi T, Vander Elst I, Zeegers M, Bisschops R, Van Pelt J, Roskams T, Cassiman D, Fevery J, Nevens F: Both $\mathrm{Ca}^{2+}$-dependent and independent pathways are involved in rat hepatic stellate cell contraction and intrahepatic hyperresponsiveness to methoxamine. Am J Physiol Gastrointest Liver Physiol 2007, 292:556-564.

83. Baveja R, Kresge N, Ashburn JH, Keller S, Yokoyama Y, Sonin N, Zhang JX,
Huynh T, Clemens MG: Potentiated hepatic microcirculatory response to endothelin-1 during polymicrobial sepsis. Shock 2002, 18:415-422.

84. Pannen BH, Bauer M, Zhang JX, Robotham JL, Clemens MG: Endotoxin pretreatment enhances portal venous contractile response to endothelin-1. Am J Physiol 1996, 270:H7-H15.

85. Ramond MJ, Poynard T, Rueff B, Mathurin P, Théodore C, Chaput JC, Benhamou JP: A randomized trial of prednisolone in patients with severe alcoholic hepatitis. N Engl J Med 1992, 326:507-512.

86. Rafailidis S, Ballas K, Psarras K, Pavlidis T, Emoniotou E, Papamichali R, Kalodimos G, Marakis G, Sakadamis A, Koukoulis G: Effect of early bosentan administration on the development of esophageal varices in cirrhotic rats: experimental study in Wistar rats. J Gastroenterol 2008, 43:897-904.

87. Sogni P, Moreau R, Gomola A, Gadano A, Cailmail S, Calmus Y, Clozel M, Lebrec D: Benificial hemodynamic effects of bosentan, a mixed ET(A) and ET(B) receptor antagonist, in portal hypertensive rats. Hepatology 1998, 28:655-659.

88. Reichen J, Gerbes AL, Steiner MJ, Sägesser H, Clozel M: The effect of endothelin and its antagonist bosentan on hemodynamics and microvascular exchange in cirrhotic rat liver. $J$ Hepatol 1998, 278:1020-1030.

89. Humbert M, Segal ES, Kiely DG, Carlsen J, Schwierin B, Hoeper MM: Results of European post-marketing surveillance of bosentan in pulmonary hypertension. Eur Respir J 2007, 30:338-344

90. Hoeper MM, Halank M, Marx C, Hoeffken G, Seyfarth HJ, Schauer J, Niedermeyer J, Winkler J: Bosentan therapy for portopulmonary hypetension. Eur Respir J 2005, 25:502-508.

91. Urbanowicz W, Sogni P, Moreau R, Tazi KA, Barriere E, Poirel O, Martin A Guimont MC, Cazals-Hatem D, Lebrec D: Tezosentan, an endothelin receptor antagonist, limits liver injury in endotoxin challenged cirrhotic rats. Gut 2004, 53:1844-1849.

92. Van de Casteele M, Omasta A, Janssens S, Roskams T, Desmet V, Nevens F, Fevery J: In vivo gene transfer of endothelial nitric oxide synthase decreases portal pressure in anaesthesised carbon tetrachloride cirrhotic rats. Gut 2002, 51:440-445.

93. Fiorucci S, Antonelli E, Brancaleone V, Sanpaolo L, Orlandi S, Distrutti E, Acuto G, Clerici C, Baldoni M, Del Soldato P, Morelli A: NCX-1000, a nitric oxidereleasing derivative of ursodeoxycholic acid, ameliorates portal hypertension and lowers norepinephrine-induced intrahepatic resistance in the isolated and perfused rat liver. J Hepatol 2003, 39:940-946.

94. Berzigotti A, Bellot P, De Gottardi A, Garcia-Pagan JC, Gagnon C, Spénard J, Bosch J: NCX-1000, a nitric oxide-releasing derivative of UDCA, does not decrease portal pressure in patients with cirrhosis: results of a randomized, double-blind, dose-escalating study. Am J Gastroenterol 2010, 105:1094-1101.

95. Zafra C, Abraldes JG, Turnes J, Berzigotti A, Fernández M, Garca-Pagán JC, Rodés J, Bosch J: Simvastatin enhances hepatic nitric oxide production and decreases the hepatic vascular tone in patients with cirrhosis. Gastroenterology 2004, 126:749-755.

96. Hackam DG, Mamdani M, Li P, Redelmeier DA: Statins and sepsis in patients with cardiovascular disease: a population-based cohort analysis. Lancet 2006, 367:413-418

97. Janda S, Young A, Fitzgerald JM, Etminan M, Swiston J: The effect of statins on mortality from severe infections and sepsis: a systematic review and meta-analysis. J Crit Care 2010, 25:656.e7-22.

98. Arabi YM, Aljumah A, Dabbagh O, Tamim HM, Rishu AH, Al-Abdulkareem A Knawy BA, Hajeer AH, Tamimi W, Cherfan A: Low-dose hydrocortisone in patients with cirrhosis and septic shock: a randomized controlled trial. CMAJ 2010, 182:1971-1977.

99. Laleman W, Wilmer A, Evenepoel P, Elst IV, Zeegers M, Zaman Z, Verslype C, Fevery J, Nevens F: Effect of the molecular adsorbent recirculating system and Prometheus devices on systemic haemodynamics and vasoactive agents in patients with acute-on-chronic alcoholic liver failure. Crit Care 2006, 10:R108.

100. Laleman W, Wilmer A, Evenepoel P: Review article: non-biological liver support in liver failure. Aliment Pharmacol Ther 2006, 23:351-363.

\section{doi:10.1186/cc10424}

Cite this article as: Verbeke $L$, et al.: Bench-to-bedside review: Acute-onchronic liver failure - linking the gut, liver and systemic circulation. Critical Care 2011, 15:233. 